\title{
EFFECTS OF ENDOTHELIN-1 ON RENAL MICROVASCULATURE MEASURED USING QUANTITATIVE ULTRASOUND
}

\author{
Michael F. Insana, John G. Wood, ${ }^{\dagger}$ Timothy J. Hall, Glendon G. Cox \\ and LINDA A. HARRISON \\ Departments of Radiology, ${ }^{\dagger}$ Surgery, and ${ }^{\ddagger}$ Physiology, University of Kansas Medical Center,
} Kansas City, KS, USA

(Received 8 March 1995; in final form 17 May 1995)

\begin{abstract}
Renal vascular resistance is an important feature of kidney function and disease. To maintain adequate blood flow, renal vascular resistance varies in response to changes in systemic pressure. Vascular resistance is largely determined by arteriolar diameter, which is regulated by local and systemic factors. We used quantitative ultrasound techniques to follow renal vascular changes in anesthetized dogs during local intraarterial infusion of a potent vasoconstrictor, endothelin-1 (ET-1). Average arteriolar diameters were estimated by analyzing echo-signal spectra $(5-15 \mathrm{MHz})$ obtained from renal cortex in vivo before, during, and after ET-1 infusion. At calculated arterial concentrations of $0.01 \mathrm{nM}, 0.1 \mathrm{nM}$, and $1.0 \mathrm{nM}, \mathrm{ET}$ 1 reduced the average arteriolar diameter of $38 \pm 2 \mu \mathrm{m}$ by $2 \%, 63 \%$, and $91 \%$, respectively, without producing a significant change in systemic blood pressure. Changes in scatterer size were consistent with the observed changes in renal hemodynamics detected using Doppler techniques. In addition, acoustic attenuation was found to increase with ET-1 concentration. These data suggest that quantitative ultrasound methods are sensitive to changes in renal arteriolar diameter, and may be a new noninvasive method for continuously monitoring changes in vascular resistance.
\end{abstract}

Key Words: Arterioles, Backscatter, Doppler, Endothelin, In vivo, Kidney, Perfusion, Resistive index, Scatterer size, Ultrasound, Vascular

\section{INTRODUCTION}

The active role of vascular endothelial cells in the regulation of vascular resistance throughout the body is just emerging (Kon et al. 1991; Simonson 1993). Under normal physiological conditions, endothelial cells respond to changes in the mechanical and chemical environments of blood vessels by altering the rate of formation of several factors. Adequate tissue perfusion depends to a large extent on a balance between the release of vasodilating and vasoconstricting factors from the endothelium. For example, nitric oxide and prostacyclin are important endothelium-derived relaxing factors that have been recently identified. These short-acting vasodilators work together with endothelin-1 (ET-1), a long-acting and potent vasoconstrictor, to regulate perfusion by stimulating vascular smooth muscle and through other mechanisms (Kon et al. 1991). Of all tissues, the highest concentration

Address correspondence to: Michael F. Insana, Department of Radiology, University of Kansas Medical Center, 3901 Rainbow Boulevard, Kansas City, KS 66160-7234, USA.
(Kitamura et al. 1989) and greatest sensitivity to the effects of ET-1 (Pernow et al. 1988) are found in the kidney. The role of ET-1 in pathophysiological conditions is currently the subject of intense international research activity. For example, evidence suggests that ET-1 is a critical factor in the development of several renal disorders, such as acute renal failure (Tomita et al. 1989) and cyclosporine-mediated renal toxicity (Kon et al. 1990). There are currently no reliable, noninvasive techniques for detecting the gradual and progressive reduction in renal blood flow that occurs prior to irreversible injury.

Our previous experience suggests that quantitative ultrasound may provide such a technique. We found that acoustically-derived estimates of the average scatterer size $(5.0-15.0 \mathrm{MHz})$ were able to follow changes in the diameter of renal arterioles caused by modifications in renal arterial pressure (Insana et al. 1992). The current study was designed to determine the sensitivity of scatterer size estimates for detecting changes in arteriolar diameter during continuous intrarenal infusions of ET-1. The study also included color-flow 
imaging and pulsed-Doppler data to independently monitor the effects of ET-1 on renal hemodynamics.

\section{MATERIALS AND METHODS}

Seven male mongrel dogs weighing between 22 and $31 \mathrm{~kg}$ were studied immediately following an unrelated experiment (Wood et al. 1994). Anesthesia was induced by an intravenous (IV) injection of $\alpha$-chloralose $\left(120 \mathrm{mg} \mathrm{kg}^{-1}\right)$ and maintained by a continuous infusion of $\alpha$-chloralose at a rate of $40 \mathrm{mg} \mathrm{kg}^{-1} \mathrm{~h}^{-1}$. The dogs were intubated and ventilated with room air, and the body temperature was maintained at $35-37^{\circ} \mathrm{C}$ using a homeothermic blanket system. The femoral artery was cannulated for measurement of systemic arterial pressure, and the femoral veins were cannulated to introduce fluids. Animals remained well hydrated by continuous IV infusion of lactated Ringer's solution. The left kidney was exposed transabdominally through a midline incision. A latex transducer cover filled with saline was placed directly on the kidney surface to acoustically couple the transducers. The left ureter was cannulated for timed urine collections, and the left renal artery was cannulated with a 24gauge $\times \frac{3}{4}$-in ( $19 \mathrm{~mm}$ ) Surflo ${ }^{\mathrm{TM}}$ catheter (Terumo Medical Corp., Elkton, MD, USA). In preliminary experiments, our inability to successfully use metal catheters in the renal artery made the flexibility of the teflon catheter essential. The arterial cannula was then connected to PE-50 tubing and immediately infused with phosphate buffered saline (PBS, pH 7.4) containing $0.2 \%$ bovine serum albumin (BSA) to prevent clotting of the catheter.

\section{ET-1 infusate preparation}

Intrarenal infusions of ET-1 (human, porcine endothelin-1; American Peptide Company, Sunnyvale, CA, USA ) were used at three different concentrations in each animal. Endothelin was dissolved into the vehi- cle (PBS-BSA), and infusate concentrations were determined using

$$
\text { Infusate Conc }=\frac{\text { Blood Conc } \times \text { Blood Flow }}{\text { Infusate Rate }} .
$$

The infusate rate was fixed at $0.1 \mathrm{ml} / \mathrm{min}$ throughout the experiment. Based on the results of Ito et al. (1991), we chose to investigate three calculated blood concentrations, $0.01 \mathrm{nM}, 0.1 \mathrm{nM}$, and $1.0 \mathrm{nM}$, that span the range of arteriolar sensitivity to ET-1. Note that the molecular weight of ET-1 is 2491.8 AMU, so that a concentration of $1.0 \mathrm{nM}$ equals $2.49 \mathrm{ng}$ ET-1 per $\mathrm{ml}$ of vehicle. Assuming a renal blood flow of 3.8 $\mathrm{ml} \mathrm{g}_{\text {kidncy }}^{-1} \min ^{-1}$ (Nizet et al. 1967) and a kidney weight of $70 \mathrm{~g}$, the three infusate concentrations were calculated to be $0.0662 \mu \mathrm{g} / \mathrm{ml}(0.01 \mathrm{nM}), 0.662 \mu \mathrm{g} /$ $\mathrm{ml}(0.10 \mathrm{nM})$, and $6.62 \mu \mathrm{g} / \mathrm{ml}(1.00 \mathrm{nM})$. Using a similar experimental design and approximately $0.1 \mathrm{nM}$ ET-1 blood concentration, Miura et al. (1991) found that vasoconstriction begins after $5 \mathrm{~min}$ of infusion. At the end of our experiments, the left kidney was weighed and the actual ET-1 blood concentrations for that experiment were calculated. These data are summarized in Table 1.

\section{Scatterer size estimates}

A single element ultrasonic transducer, operated in pulse-echo mode, was positioned in the saline-filled transducer cover. Broadband echo signals were time gated to record data only from the renal cortex in the manner reported previously [( Insana et al. 1992), Fig. 1]. A $10 \mathrm{MHz}$, spherically focused, 19-mm diameter, circular transducer ( $\mathrm{f}-$ number $\sim 2.8$ and depth of field $\sim 8.7 \mathrm{~mm}$ ) was used. Ten echo waveforms were recorded for each acoustic measurement reported, where the lateral translation distance between waveform recordings was approximately one beam width, i.e., $1 \mathrm{~mm}$

Table 1. Renal arterial ET-1 blood concentrations for the seven studies.

\begin{tabular}{|c|c|c|c|c|c|}
\hline \multirow{2}{*}{$\begin{array}{l}\text { Experiment } \\
\text { number }\end{array}$} & \multirow{2}{*}{$\begin{array}{c}\text { Body weight } \\
(\mathrm{kg})\end{array}$} & \multirow{2}{*}{$\begin{array}{l}\text { Left kidney weight } \\
\qquad(\mathrm{g})\end{array}$} & \multicolumn{3}{|c|}{ ET-1 blood conc. (nM) } \\
\hline & & & Low & Medium & High \\
\hline 1 & 26.6 & 70.0 & 0.0100 & 0.100 & 1.00 \\
\hline 2 & 26.2 & 79.5 & 0.0088 & 0.088 & 0.88 \\
\hline 3 & 22.0 & 75.5 & 0.0093 & 0.093 & 0.93 \\
\hline 6 & 27.5 & 83.0 & 0.0084 & 0.084 & 0.84 \\
\hline 7 & 23.6 & 108.5 & 0.0064 & 0.064 & 0.64 \\
\hline 9 & 31.0 & 98.0 & 0.0071 & 0.071 & 0.71 \\
\hline 10 & 31.0 & 82.0 & 0.0085 & 0.085 & 0.85 \\
\hline Ave $\pm S E$ & $26.8 \pm 3.4$ & $85.2 \pm 13.4$ & $0.0084 \pm 0.0012$ & $0.084 \pm 0.012$ & $0.84 \pm 0.12$ \\
\hline
\end{tabular}

Although the same infusate concentration was used for each experiment, the actual computed blood concentrations varied with kidney weight as indicated. Ave = average; Conc. = concentration; ET-1 = endothelin-1. 

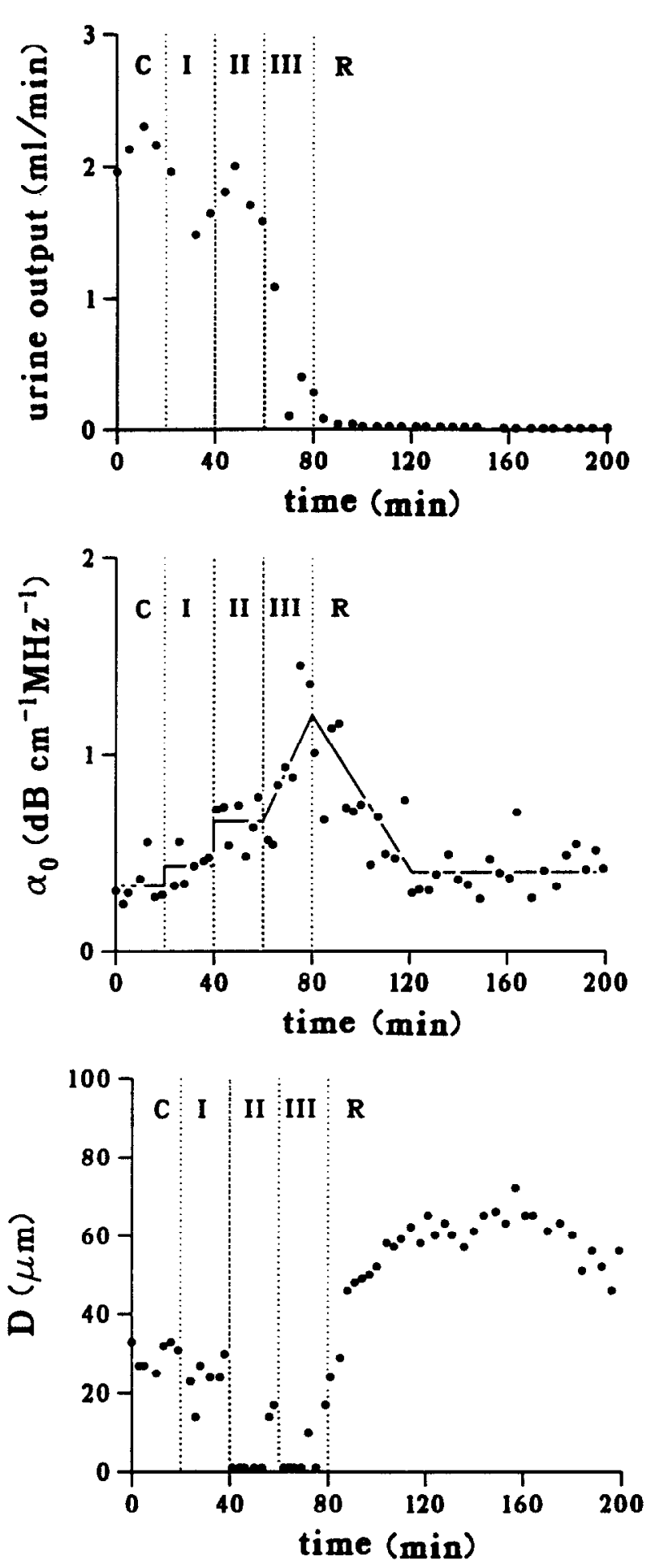

Fig. 1. Data acquired in one of three experiments in the main group ( $\operatorname{dog} 6$ ) to illustrate the effects of exogenous cndothelin-1 (ET-1) in a dog kidney. The attenuation slope $\alpha_{0}$ and the average scatterer size $D$ were measured from echo-waveform data sets acquired every $3 \mathrm{~min}$. Urine output was measured every $5 \mathrm{~min}$. Following a control period (C), three concentrations of ET-1 were infused: $I=0.01 \mathrm{nM}$, II $=0.1 \mathrm{nM}$, and III $-1.0 \mathrm{nM}$. The final $120 \mathrm{~min}$ were the recovery ( $R$ ) period. Solid lines on the $\alpha_{0}$ plot are the values used to estimate scatterer size values. at the radius of curvature. Radiofrequency signals were digitized at (nominally) 8 bits and at a rate of $5 \times 10^{7}$ samples per second, under the control of a personal computer. The transducer was positioned so that the renal cortex was placed near the radius of curvature of the transducer, and the beam axis was parallel to the predominant nephron orientation. Each $10 \mu \mathrm{s}$ waveform segment analyzed was multipled by a Hanning window function. Power spectral density functions were computed for the windowed waveform segments in a data set via a fast-Fourier transform (FFT) algorithm to find an average. Although data acquisition was synchronized to breathing, occasionally the cortical region of interest migrated axially over many breaths. 'To compensate, each waveform was visually inspected and the position of the range gate was adjusted before processing to avoid including any noncortical tissues. The $10 \mu$ s gate corresponded to $\sim 7.9 \mathrm{~mm}$ of tissue, and the thickness of the cortex was usually $10 \mathrm{~mm}$ to $12 \mathrm{~mm}$ ensuring a reasonably homogeneous sample volume. Specular scattering from arcuate arteries and veins allowed us to identify the corticomedullary junction. Digitized data were transferred after the experiment to a workstation for off-line analysis.

The average spectrum for a data set was used to estimate backscatter coefficients versus frequency from which the average scatterer sizes $(D)$ were computcd. The diameter of cortical arterioles is directly related to the shape of the backscatter coefficient versus frequency curve between 5 and $15 \mathrm{MHz}$ (Insana ct al. 1992). The integrated backscatter coefficient (IBC) was calculated by averaging backscatter coefficients over the same frequency range. Procedures for measuring and interpreting acoustic properties from echo spectra were described previously (Insana and Hall 1990; Insana et al. 1994).

\section{Statistical analyses}

Mean values \pm 1 standard error (SE) are reported unless otherwise indicated. A two-sided, paired $t$-test was used to test the significance of changes in scatterer size between each test period and the control (Snedecor and Cochran 1989). Differences were considered statistically significant at $p \leq 0.05$. The Shapiro-Francia statistic (Shapiro and Francia 1972) indicated that it was reasonable to assume the scatterer size estimates for a given time period and experiment were normally distributed. Exceptions occurred in time periods where the minimum $D$ value of $1 \mu \mathrm{m}$ was common. Given the sample means and variances of the results, and specifying that type I and type II errors could be no greater than $5 \%$, we estimated that three animal experiments provided sufficient statistical power [Eq. 2 in Insana et al. (1992)]. 

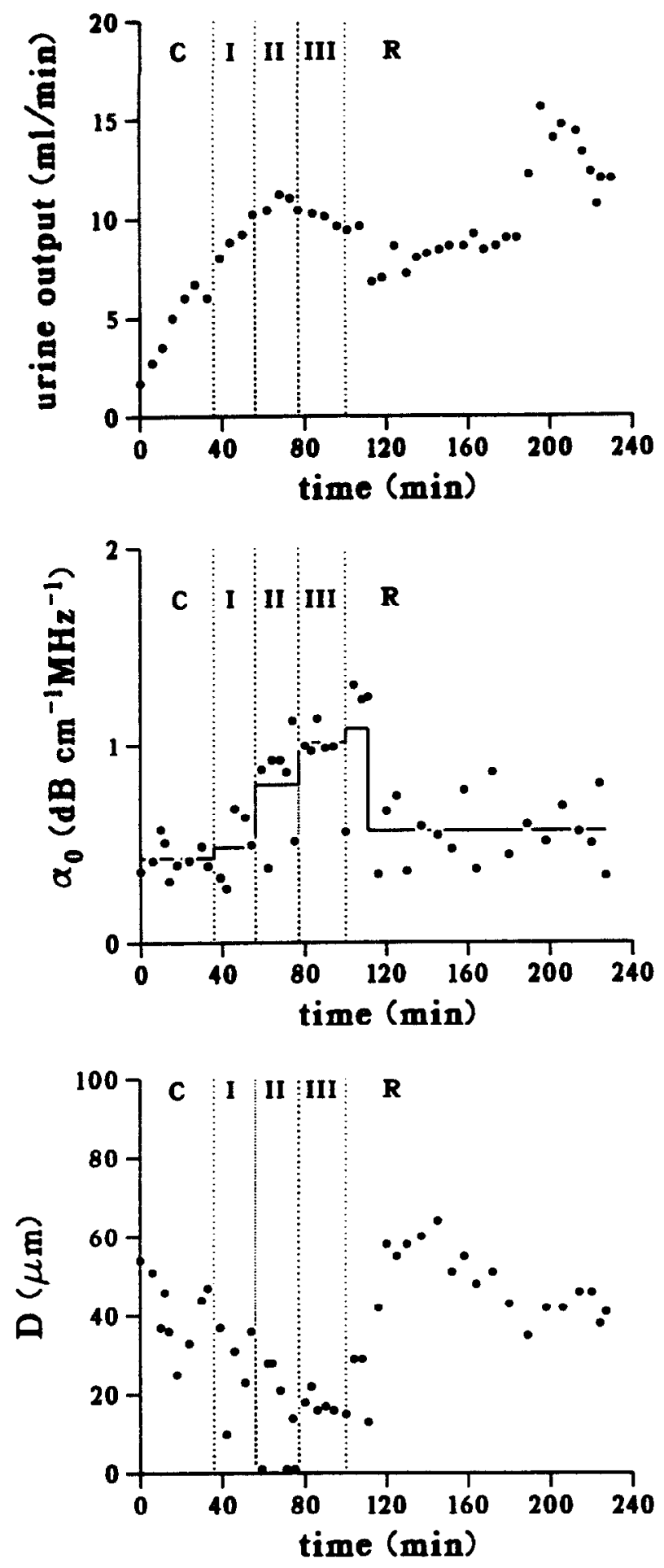

Fig. 2. Data acquired in another experiment $(\operatorname{dog} 2)$ where the diuretic mannitol was infused systemically. Otherwise, conditions were the same as those of the main group.

\section{Attenuation estimates}

Results in the next section show that the renal cortex increases its attenuation of sound as ET-1 was infused. Accurate estimation of scatterer sizes requires
Volume 21, Number 9.1995

precise knowledge of attenuation along the beam path (Insana et al. 1994). Therefore, to accurately monitor changes in $D$, it was necessary to estimate cortical attenuation throughout the time course of the experiments. A spectral difference technique recently described by Wilson et al. (1994) was selected for this purpose [method c in Wilson et al. (1994)].

Each echo-signal data set was analyzed to estimate attenuation as follows. The first $1.28 \mu \mathrm{s}$ (64 points) of each waveform were multiplied by a 64 point (Hanning) window function. The power spectra of the windowed segments were computed, and the amplitudes of the average spectrum were converted to decibels. Next, the $1.28 \mu \mathrm{s}$ window function was delayed by $0.64 \mu \mathrm{s}$ ( $50 \%$ overlap) and the average spectrum in decibels was again computed. The process was repeated until 13 average echo spectra, corresponding to 13 equally-spaced depths in the tissue, were obtained. At each frequency in the bandwidth, the slope of the spectral amplitude (decibel) versus depth (centimeters) was computed to find the attenuation coefficient $\alpha(\mathrm{dB} / \mathrm{cm})$ at that frequency. $\Lambda$ plot of $\alpha(f)$ was obtained for each data set.

The small amount of data available in the data sets could not yield precise attenuation estimates. Consequently, attenuation was modeled as a linear function of frequency, and the slope of the attenuation coefficient versus frequency curve, $\alpha_{0}$, was used in the scatterer size estimation.

The method was tested by comparing results ohtained by this spectral difference method with those from a standard narrow-band through-transmission method (Madsen et al. 1982). The attenuation coefficient for a graphite-in-agar test sample $(c=1541 \mathrm{~m} /$ s) measured with the through-transmission method was best described by the equation $\alpha(f)=0.34 f^{1.25}$, $r=0.999$ for the range $2 \mathrm{MHz} \leq f \leq 13 \mathrm{MHz}$. Assuming a linear frequency dependence for the same echo data, i.e., $\alpha(f)=\alpha_{0} f$, we found $\alpha_{0}=0.69$ and $r=0.995$. Using the spectral difference method to estimate attenuation from the phantom, we found $\alpha_{0}$ $=0.65$ and $r=0.972$ for the range $8 \mathrm{MHz} \leq f \leq$ 14.5 MHz. The spectral difference method yielded unbiased $\alpha_{i}$ estimates but the standard error of the mean $\left(\alpha_{0}=0.65 \pm 0.10\right)$ was approximately ten times that of the through-transmission method $\left(\alpha_{0}=0.69 \pm\right.$ 0.01 ). We also searched for a systematic variation in attenuation slope with distance from the transducer. The effect on $\boldsymbol{\alpha}_{0}$ estimates was found to be within the uncertainty of the spectral difference method for our experimental conditions, and was therefore ignored.

\section{Doppler measurements}

Doppler measurements were obtained in two additional animal studies under the same experimental con- 


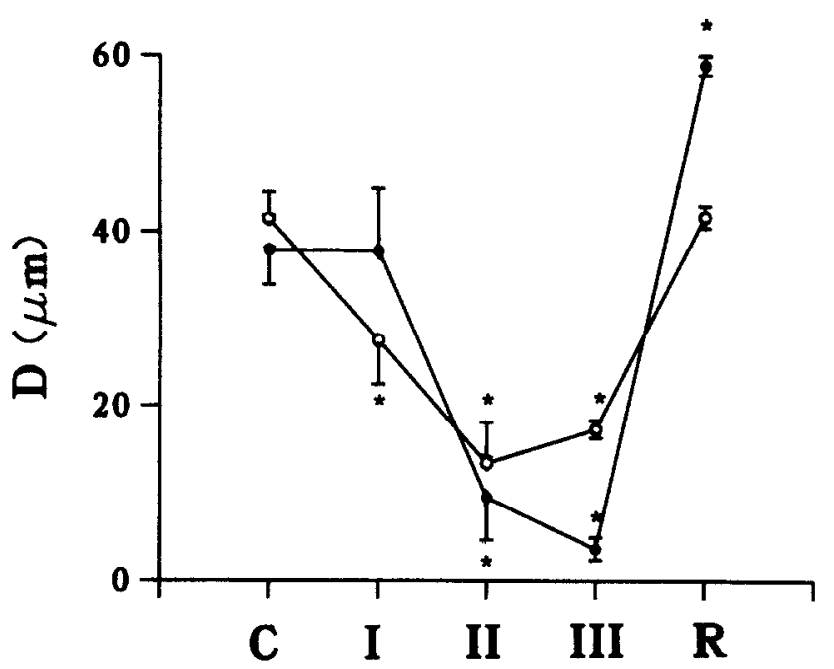

Fig. 3. Summary of results from the main group (๑) and the mannitol experiment $(O)$ showing the effects of exogenous ET-1 on scatterer size estimates $(D)$ measured in renal cortex. The means $\pm 1 \mathrm{SE}$ of all the $D$ data within a period and for all animals are plotted. $\mathrm{C}$ indicates the mean from the control period; I, II, and III represent the three ET-1 infusate concentrations of $0.01 \mathrm{nM}, 0.1 \mathrm{nM}$, and $1.0 \mathrm{nM}$, respectively; and $R$ indicates the average value from the plateau during the recovery period. $* p \leq 0.05$ compared to the control values.

ditions as other acoustic measurements. An Acuson $128 \mathrm{XP} / 10$ ultrasound scanner (Acuson, Mountain View, CA, USA) and multifrequency L5 probe were used, although the multifrequency feature of the probe was not active. The tip of the $5 \mathrm{MHz}$ linear array was placed in a saline-filled transducer cover that was coupled directly to the surface of the left kidney. Once a region of interest in the long-axis plane of the kidney was selected, the probe was clamped in place for the duration of the study. Doppler spectra were recorded from an interlobar artery that was approximately colinear with the beam axis. The resistive index (RI) was computed from spectral data using built-in software as follows:

$$
\mathrm{RI}=\left(f_{s}-f_{d}\right) / f_{s},
$$

where $f_{s}$ is the peak systolic frequency shift and $f_{d}$ is the end diastolic frequency shift. Increasing RI values signify an increase in vascular resistance. Color-flow images were also obtained periodically in the same scan plane without changing system parameters, such as gain. All data were recorded during the expiration phase of the breathing cycle.

\section{RESULTS}

\section{Quantitative ultrasound}

Figure 1 describes the data for one of the three experiments in the main group. The first 20 min were a control period $(C)$, where measurements were made every 3 min while PBS-BSA was infused into the renal artery. During the next three 20 -min periods, labelled I, II, and III, ET-1 was infused to produce nominal blood concentrations of $0.01 \mathrm{nM}, 0.1 \mathrm{nM}$, and $1.0 \mathrm{nM}$. PBS-BSA was again infused during the final 120-min recovery period $(R)$. To avoid introducing attenuation uncertainty into the scatterer size estimates, $D$ values were determined by using the average $\alpha_{0}$ computed for a time period (solid lines in Fig. 1). During period III and at the beginning of the recovery phase, a linear model for $\alpha_{0}$ was used.

ET-1 caused a decrease in urine output and average scatterer size in a dose-dependent manner, as it increased $\alpha_{0}$. These are signs of increased vascular resistance caused by vasoconstriction. During recovery, in the experiment of Fig. 1, scatterer size estimates rose to a level above the average control value within the first few minutes. In another experiment (not shown), $D$ values remained minimal 40 min into the recovery before increasing to a plateau above the average control value for $D$. In each recovery period, once vasoconstriction was ended, $D$ values were greater than the control. Urine flow did not return during the 2-h recovery period, suggesting that the tissue had been damaged.

One additional experiment was performed under the same conditions as the main group, except that a $20 \%$ mannitol solution was continuously infused into a femoral vein at a rate of $10 \mathrm{ml} / \mathrm{min}$ (Fig. 2). The diuretic increased urine flow by a factor of five, and seemed to offer some protection from ET-1-induced ischemia. Note that midway into the recovery, urine flow increased significantly and $D$ estimates indicated that the mean arteriolar diameter returned to control values. Even with the diuretic, the first sign that urine flow had recovered occurred $80 \mathrm{~min}$ after ET-1 infusion was stopped.

Figure 3 summarizes the results from the three animal experiments in the main group (solid points) and the single experiment using mannitol (open

Table 2. Comparing the effects of ET-1.

\begin{tabular}{lllll}
\hline & \multicolumn{4}{c}{ Nominal ET-1 blood conc. } \\
\cline { 2 - 5 } & \multicolumn{1}{c}{$0.01 \mathrm{nM}$} & \multicolumn{1}{c}{$0.1 \mathrm{nM}$} & $1.0 \mathrm{nM}$ \\
\hline$D(\mathrm{n}=3)$ & $2.0 \pm 10.2 \%$ & $63.1 \pm 9.8 \%$ & $91.5 \pm 3.8 \%$ \\
ALD $(\mathrm{n}=7)$ & $3 \pm 1.8 \%$ & $32 \pm 8 \%$ & $76 \pm 7 \%$ \\
\hline
\end{tabular}

The percentage reduction $( \pm S E)$ in scatterer sizes $(D)$ from experiments in the main group are compared with the percentage reduction in rabbit renal arteriole luminal diameters (ALD) observed directly by Ito et al. (1991) using photomicrographs. Conc. $=$ concentration; ET-1 = endothelin-1. 
Table 3. Average RI values ( \pm 1 SD) estimated from Doppler traces in two animal experiments.

\begin{tabular}{|c|c|c|c|c|c|c|}
\hline \multirow[b]{2}{*}{ RI } & \multirow[b]{2}{*}{ Control } & \multicolumn{3}{|c|}{ Nominal ET-1 blood conc. } & \multirow{2}{*}{$\begin{array}{l}\text { 30-min } \\
\text { recovery }\end{array}$} & \multirow{2}{*}{$\begin{array}{l}\text { 45-min } \\
\text { recovery }\end{array}$} \\
\hline & & $0.01 \mathrm{nM}$ & $0.1 \mathrm{nM}$ & $1.0 \mathrm{nM}$ & & \\
\hline Dog 9 & $0.37 \pm 0.03$ & $0.37 \pm 0.03$ & $0.40 \pm 0.04$ & $0.47 \pm 0.03$ & $\mathrm{NA}$ & NA \\
\hline Dog 10 & $0.37 \pm 0.06$ & $0.37 \pm 0.03$ & $0.37 \pm 0.03$ & $0.43 \pm 0.05$ & 0.57 & $0.71 \pm 0.05$ \\
\hline
\end{tabular}

Values are an average of between 3 and 16 measurements. Conc. $=$ concentration; ET-1 $=$ endothelin-1: NA $=$ not available; $\mathbf{R I}=$ resistive index .

points ). $D$ estimates acquired within a time period and for all experiments in the group were averaged, and the mean values $\pm 1 \mathrm{SE}$ were plotted. During the control period, we measured $D=38 \pm 2 \mu \mathrm{m}$ as the average value for the four animals studied. In the mannitol experiment, the mean scatterer size for the recovery period was computed only where $D$ was approximately constant, i.e., for $t \geq 180 \mathrm{~min}$. A significant reduction in scatterer size was observed for ET-1 concentrations of $0.1 \mathrm{nM}$ and $1.0 \mathrm{nM}$. The dose-dependent response in $D$ was similar to the changes in luminal diameter observed by Ito et al. (1991) in rabbit renal arterioles (Table 2). The increase in scatterer size during the recovery period relative to the control $(p \leq 0.001)$, suggests that the arterioles were dilated during the recovery phase for the main group. However, when mannitol was used (Fig. 2), arterioles dilated early in the recovery phase but returned to the control value $(p=$ 0.96 ) and urine output increased. The attenuation slope increased dramatically with ET-1 concentration in each experiment. It returned to near-control values quickly when mannitol was used and more slowly without mannitol.

\section{Doppler ultrasound}

Doppler measurements were obtained from dogs 9 and 10 near the end of each period. Average RI are listed in Table 3 and color-flow images for dog 10 are shown in Fig. 4. Overall, the standard deviation of RI estimates in Table 3 are similar to those reported in reproducibility studies (London et al. 1993). The Doppler-gated volume was located within the interlobar artery as shown by the arrow in Fig. 4. Although an attempt was made to keep the Doppler angle small, the built-in angle correction feature was applied when computing RI values.

Only minor changes in RI values and color-flow images were observed in periods I and II relative to the control. Then, midway into period III, over just a few seconds time, the color-flow images indicated a near-total loss of blood perfusion and it became impossible to record Doppler spectra. After $10 \mathrm{~min}$ of recovery, the color-flow images showed some restoration of blood flow in the larger vessels of the kidney. The increase in blood flow was so gradual that a Doppler spectrum could not be obtained from the interlobar artery until $30 \mathrm{~min}$ into the recovery (Fig. 4, Re). During recovery the RI was elevated, indicating that the vascular resistance was greater throughout the recovery period than during the control period. Flow continued to increase throughout the recovery (Fig. 4, RI) period and the RI remained high.

\section{DISCUSSION}

The results demonstrate that scatterer size estimates are valid indicators of the changes in renal microstructure caused by ET-1. In the $5-15 \mathrm{MHz}$ range of frequencies, scatterer size estimates describe the cross-sectional diameter of renal arterioles. Scatterer size $(D)$ estimates clearly depend on ET-1 concentration, follow the same patterns of luminal diameter variations observed directly by Ito et al. (1991), and are consistent with the changes in blood flow seen by color-flow imaging.

Maintaining a constant systemic pressure throughout was an important feature of our experimental design. By infusing ET-1 intrarenally at rates that did not produce systemic pressor responses, we were able to observe the direct response of the kidney to ET-1 without the complications of systemic (autoregulatory) changes in renal vascular resistance. Results obtained during ET-1 infusion periods showed that vasoconstriction did occur and that renal blood flow was reduced in a manner consistent with other reports (Stacy et al. 1990). However, results obtained during the recovery period are less straightforward. Colorflow images indicated reperfusion (Fig. 4, Re and Rl), and the scatterer size estimates suggested that arterioles were dilated with respect to the control (Fig. 3). Nevertheless, the RI was higher than control values and urine flow did not recover.

It is likely that the loss of urine flow resulted from renal tubular damage following 30-40 min of reduced blood flow (Zager et al. 1987). Tubular epithelial injury is thought to occur when blood flow returns, due 

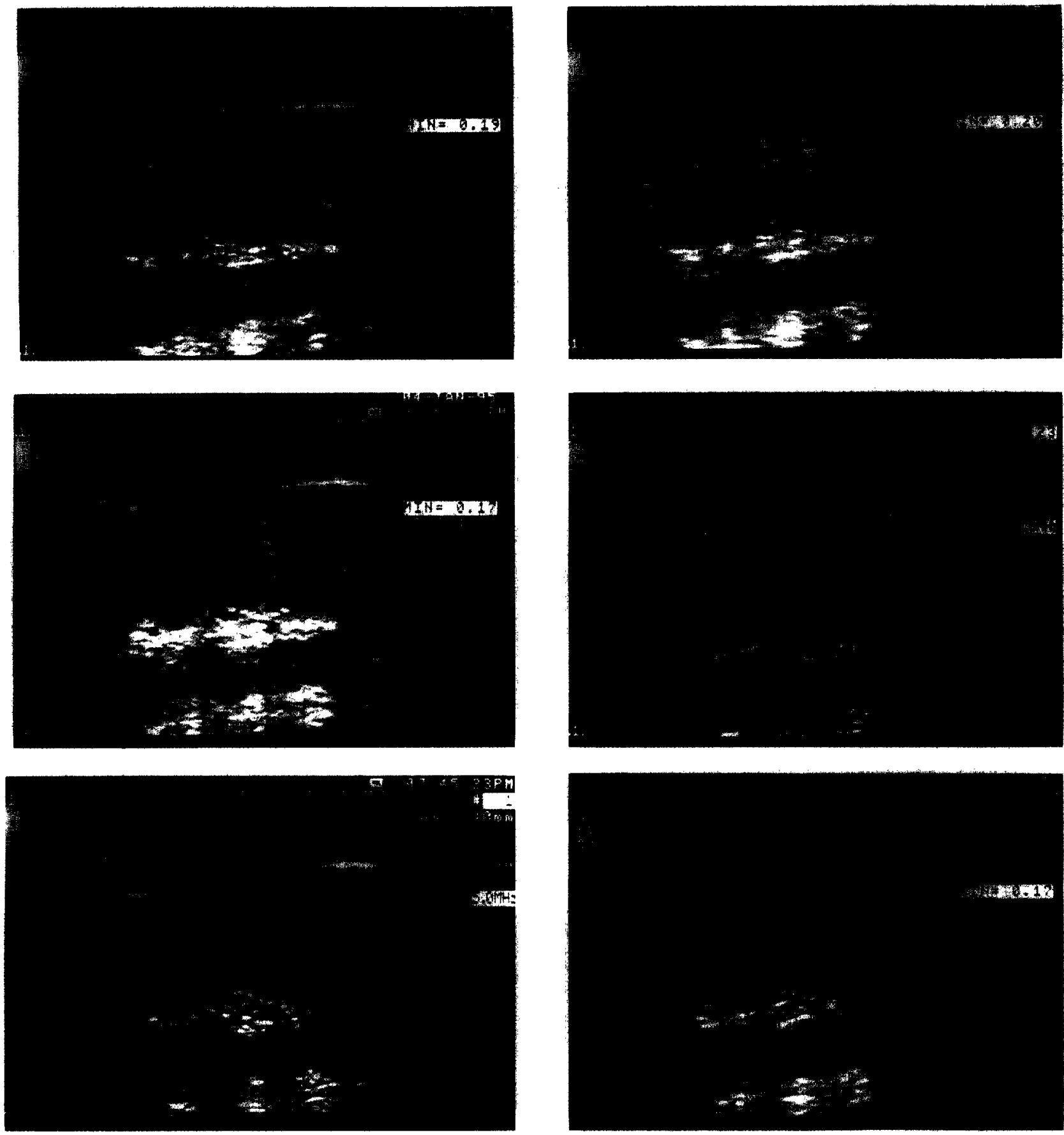

Fig. 4. Color-flow images of the left kidney of dog 10 were recorded during the control period (C); during endothelin1 (ET-1) infusions of concentrations (I), (II), and (III); and during early (Re) and late (RI) recovery. The location of the interlobar artery used to acquire velocity spectra is indicated by the arrow. The Doppler window length was approximately $4 \mathrm{~mm}$, and the color coding corresponds to a velocity range of $\pm 12 \mathrm{~cm} / \mathrm{s}$. Some aliasing was allowed in the initial color flow images (the blue) to increase system sensitivity to low flow in the later images. Average urine outputs during the six periods were: $\mathrm{C}=0.33 \pm 0.03 \mathrm{ml} / \mathrm{min} ; \mathrm{I}=0.40 \pm 0.04 \mathrm{ml} / \mathrm{min}$; II $=0.47 \pm 0.07$ $\mathrm{ml} / \mathrm{min} ;$ III $=0.32 \pm 0.22 \mathrm{ml} / \mathrm{min} ; \mathrm{Re}=0.06 \pm 0.02 \mathrm{ml} / \mathrm{min} ;$ and $\mathrm{Rl}=0.08 \pm 0.02 \mathrm{ml} / \mathrm{min}$

to the formation of reactive oxygen metabolites (Walker and Shah 1991). We found that mannitol infusion seemed to blunt the effects of ET-1-induced injury (Fig. 3), which is consistent with this hypothesis. The protective features of mannitol are thought to be caused by its diuretic (Zager et al. 1991) and 
antioxidant (Zager et al. 1992) properties that are likely to reduce reactive oxygen metabolite levels within the kidney.

It is more difficult to explain why scatterer sizes measured during recovery were greater than control values, suggesting vasodilation, when blood flow was reduced and $\mathrm{RI}$ values were elevated, suggesting vasoconstriction. Because of many feedback mechanisms in the kidney, more information is required to explain with any certainty the mechanisms that lead to these observations. However, with our current understanding, we conjecture that differences in the sensitivity to ET-1 of afferent and efferent arterioles (Badr et al. 1989; Ito et al. 1991; Kon et al. 1991 ) could produce such data. We could not detect sensitivity differences during periods I, II, and III because both vessel types respond within minutes, while echo-signal data sets were recorded every 3-5 min. Because ET-1 effects were long acting, sensitivity differences were detectable during recovery. If efferent arterioles are more sensitive than afferents (Badr et al. 1989; Kon et al. 1991 ), then afferent arterioles would be expected to relax first. During periods of reduced blood flow, vasodilators accumulate in blood vessels. Once the effects of ET-1 have worn off, the afferent arterioles may become dilated relative to the control period in response to these dilators. As a result, blood flow may gradually begin to return, although vascular resistance remains high because the efferent arterioles are still constricted. Furthermore, the acoustic backscatter intensity is known to be very sensitive to the average scatterer size for Rayleigh scattering $(\pi D / \lambda<1)$, so that the larger afferent arterioles would backscatter more sound than the efferent arterioles. Hence, the frequency dependence of the backscatter coefficient was determined primarily by properties of the relaxed afferent arterioles. During recovery, fewer structures per unit volume were scattering sound at frequencies in the analysis bandwidth. Consequently, kidneys recovering from the effects of ET-1 would produce Doppler data that indicated vasoconstriction, because blood flow was limited by the smaller efferent arterioles, and scatterer size estimates that indicated vasodilation, since the echo spectrum would be determined primarily by the larger afferent arterioles.

To test this hypothesis, we compared integrated backscatter coefficient (IBC) measurements during the control and recovery periods for the studies in the main group to see if fewer scatterers were indicated. IBC is proportional to the average number density of scatterers (Insana and Hall 1990). We found that IBC was reduced in recovery $\left(\mathrm{IBC}=1.67 \times 10^{-3} \pm 0.07 \times\right.$ $\left.10^{-3}\right)$ as compared to the control $\left(\mathrm{IBC}=2.36 \times 10^{-3}\right.$ $\left.\pm 0.11 \times 10^{3}\right)$. This $30 \%$ reduction was significant $(p=0.0002)$.

A similar result was found in our earlier studies using $D$ and IBC to follow renal autoregulation during ischemia (Insana et al. 1992). Kidneys are known to respond to a drop in systemic pressure by dilating afferent arterioles and constricting efferent arterioles in an attempt to restore filtration pressure. Captopril, which blocks this type of efferent constriction, was found to increase IBC without changing scatterer size signiticantly. We hypothesized in the earlier study that the increase in IBC was caused by an increase in the number density of scatterers contributing to the echo spectrum in the analysis bandwidth. Results of the current study provide further support for this hypothesis.

The role of ultrasonic attenuation in the process of estimating scatterer sizes was critical to the results. If the apparent increase in allenuation slope had not been accounted for, the $D$ values of Figs. 1-3 would have been biased high. Mannitol seemed to affect the time-rate of change in attenuation but not the magnitude of the change. Therefore, attenuation effects do not appear to be caused by changes in tissue hydration. Although $\alpha_{0}$ clearly increased during ET-1 infusion, mechanisms to account for that variation are unknown at this time.

We conclude that, in the $5-15 \mathrm{MHz}$ frequency range, scatterer size estimates are sensitive indicators of changes in renal microvasculature caused by ET-1induced vasoconstriction. ET-1 is an important element of many renal disease mechanisms. Its potent and longacting effects appear early in disease, before any morphologically demonstrable damage is apparent (Kon et al. 1991 ). Therefore, quantitative ultrasound methods have the potential to provide new information about early renal disease, noninvasively, for research applications. The diagnostic potential of these methods is yet to be tested under clinical conditions.

Acknowledgements - The authors would like to thank Professor Larry Sullivan for his advice. This work was supported by NIH grant R01 DK43007 and the Clinical Radiology Foundation at KUMC. Veterinary care was provided by the medical staff of the Animal Care Unit at the University of Kansas Medical Center. The experimental protocol was approved by the Institutional Animal Care and Use Committee.

\section{REFERENCES}

Badr, K. F.; Murray, J. J.: Breyer, M. D.; Takahashi, K.; Inagami, T.: Harris, R. C. Mesangial cell, glomerular, and renal vascular responses to endothelin in the rat kidney. J. Clin. Invest. 83:336342; 1989.

Insana, M. F.; Hall, T. J. Parametric ultrasound imaging from back. scatter coefficient measurements: Image formation and interpretation. Ultrason. Imaging 12:245-267; 1990.

Insana, M. F.; Hall, T. J.; Cook, L. T. Backscatter coefficient estimation using array transducers. IEEE Trans. Ultrason. 41:714-723; 1994. 
Insana, M. F.; Wood, J. G.; Hall, T. J. Identifying acoustic scattering sources in normal renal parenchyma in vivo by varying arterial and ureteral pressures. Ultrasound Med. Biol. 18:587-599; 1992.

Ito. S.: Juncos, L. A.: Nyshiro. N.: Johnson. C. S.: Carretero, O. A. Endothelium-derived relaxing factor modulates endothelin action in afferent arterioles. Hypertension 17:1052-1056; 1991.

Kitamura, K.; Tanaka, T.; Kato, J.; Eto, T.; Tanaka, K. Regional distribution of immunoreactive endothelin in porcine tissue: Abundance in inner medulla of kidney. Biochem. Biophys. Res. Commun. 161:348-352; 1989.

Kon, V.; Badr, K. F. Biological actions and pathophysiologic significance of endothelin in the kidney. Kidney Int. 40:1-12; 1991.

Kon. V.: Sugiura, M.; Inagami, T.: Harvie, B. R.; Ichikawa, I.; Hoover, R. L. Role of endothelin in cyclosporine-induced glomerular dysfunction. Kidney Int. 37:1487-1491; 1990.

London. N. J.; Aldoori, M. I.; Lodge, V. G.; Bates, J. A.; Irving, H. C.; Giles, G. R. Reproducibility of Doppler ultrasound measurement of resistive index in renal allographs. $\mathrm{Br}$. J. Radiol. 66:510-513; 1993.

Madsen. E. L.; Zagzebski, J. A.; Frank G. R. Oil-in-gelatin dispersions for use as ultrasonically tissue-mimicking materials. Ultrasound Med. Biol. 8:277-287; 1982.

Miura, K.; Yukimura, T.; Yamashita, Y.; Shimmen, T.; Okumura M.; Yamanaka, S.; Imanishi, M.; Yamamoto, K. Renal and femoral responses to endothelin-1 in dogs: Role of prostaglandins. $J$. Pharmacul. Exp. Ther. 256:11-17; 1991.

Nizet, A.; Cuypers, Y.; Deetjen, P.; Kramer, K. Functional capacity of the isolated perfused dog kidney. Pflugers Archiv. 296:179$195 ; 1967$.

Pernow, J.; Boutier, J.-F.; Franco-Cereceda, A.; Lacroix, J. S.; Ma$\operatorname{tran}, \mathbf{R}$; I undberg, J. M. Potent selective vasoconstrictor effects of endothelin in the pig kidney in vivo. Acta Physiol. Scand $134: 573-574 ; 1988$.

Shapito. S. S.: Francia. R. S. An approximate analysis of variance test for normality, J. Am. Statistical Assoc. 67:215-216; 1972 (these methods are implemented in the Wilk-Shapiro/Rankit Plots algorithm of Statistix. Analytical Software, PO Box 13204. St. Paul, MN 55113, USA).

Simonson, M. S. Endothelins: Multifunctional renal peptides. Physiol. Rev. 73:375-411; 1993.

Snedecor, G. W.; Cochran, W. G. Statistical Methods, 8th Ed. Ames: Iowa State University Press: 1989.

Stacy, D. L.: Scott. J. W.; Granger, J. P. Control of renal function during intrarenal infusion of endothelin. Am. J. Physiol. 258:F1232-F1236; 1990

Tomita, K.; Ujiie, K.; Nakanishi, T.; Tomura, S.: Matsuda, O.; Ando, K.; Shichiri, M.: Hirata, Y.; Marumo, F. Plasma endothelin levels in patients with acute renal failure. N. Engl. J. Med. 321:1127; 1989.

Walker, P. D.; Shah, S. V. Hydrogen peroxide cytotoxicity in LLCPK, cells: A role for iron. Kidney Int. 40:891-898; 1991 .

Wilson, L. S.; Neale, M. L.; Talhami, H. E.; Appleberg, M. Preliminary results from attenuation-slope mapping of plaque using intravascular ultrasound. Ultrasound Med. Biol. 20:529-542; 1994.

Wood, J. G.: Yan. Z. Y.: Davis J. M.; Cheung. L. Y. Phosphoramidon attenuates big ET-1-induced vasoconstriction in canine stomach Am. J. Physiol. 266:G311-G317; 1994.

Zager, R. A.; Bredl, C. R.; Schimpf, B. A. Direct amphotericin Bmediated tubular toxicity: Assessments of selected cytoprotective agents. Kidney Int. 41:1588-1594; 1992.

Zager, R. A.; Foerder, C; BredI, C. The influence of mannitol on myoglobinuric acute renal failure: Functional, biochemical, and morphological assessments. J. Am. Soc. Nephrol. 2:848-855; 1991.

Zager, R. A.; Tuebner, E. G.; Adler, S. Low molecular weight proteinuria exacerbates experimental ischemic renal injury. Lab. Invest. $56: 180-188 ; 1987$. 